SECTION 7. Mechanics and machine construction.

Lukyanov Aleksey Aleksandrovich undergraduate student Togliatti State University, Russia a.lukyanov@,tehnomasch.ru

Levitskih Olesya Olegovna Lead Economist Togliatti State University, Russia 1oo-05@mail.ru

Ezhelev Andrey Victorovich Post-graduate student

Togliatti State University, Russia

\title{
ANALYSIS OF WIDE BURNISHING TECHNOLOGY APPLICATION RESULTS IN MASS PRODUCTION OF CRANKSHAFTS
}

\begin{abstract}
In this paper experience of machine parts processing with surface plastic deformation technology with high productivity is presented by the processing of under-gland journal of crankshaft of Lada Priora and Lada Kalina cars example. Results of experimental studies which directed on application efficiency of proposed technology determining are presented.
\end{abstract}

Key words: crankshaft, wide burnishing, gland leak.

\section{АНАЛИЗ РЕЗУЛЬТАТОВ ВНЕДРЕНИЯ ТЕХНОЛОГИИ ШИРОКОГО ВЫГЛАЖИВАНИЯ В МАССОВОЕ ПРОИЗВОДСТВО КОЛЕНЧАТЫХ ВАЛОВ}

\begin{abstract}
Аннотация: В работе представлен опыт технологии обработки поверхностей деталей машин выглажсиванием с высокой производительностью на примере обработки подманжетной шейки вала коленчатого автомобилей Lada Приора и Lada Калина. Представлены результаты экспериментальных исследований, направленных на определение эффективности применения предложенной технологии.
\end{abstract}

Ключевые слова: вал коленчатый, широкое выглаживание, течь сальника.

Процессы обработки поверхностно-пластическим деформированием (ППД) известны с середины прошлого века. Исследованиям в данной области посвящены многие работы отечественных и зарубежных ученых $[1,2]$. В основном процессы ППД внедрялись на операциях по обработке ответственных деталей в мелкосерийном и единичном производствах.

Одной из актуальных задач являлось внедрение процесса обработки ППД в массовое производство при сохранении его основных преимуществ - гибкости в диапазоне получаемых параметров микрогеометрии и повышение микротвердости приповерхностных слоев.

Исследования в области процессов ППД в НИЛ-7 «Автомобильные технологии» Тольяттинского государственного университета ведутся длительное время. Одним из показательных результатов является успешное внедрение разработанной лаборатории новой разновидности ППД - широкого выглаживания в массовое производства ОАО «AВTOBA3» для обработки коленчатых валов автомобилей LADA (в настоящее время данные детали устанавливаются на автомобилях Lada Kalina). 
Процесс широкого выглаживания отличается от классического выглаживания тем, что подача осуществляется лишь в поперечном направлении широким самоустанавливающимся инструментом, ширина рабочей зоны которого равна длине обрабатываемой поверхности (см. рисунок 1) [3, 4]. Данное техническое решение позволило реализовать процесс обработки выглаживанием в жестко заданных условиях цикла производства, в котором процесс обработки всей детали широким выглаживанием составляет 5-6 секунд.

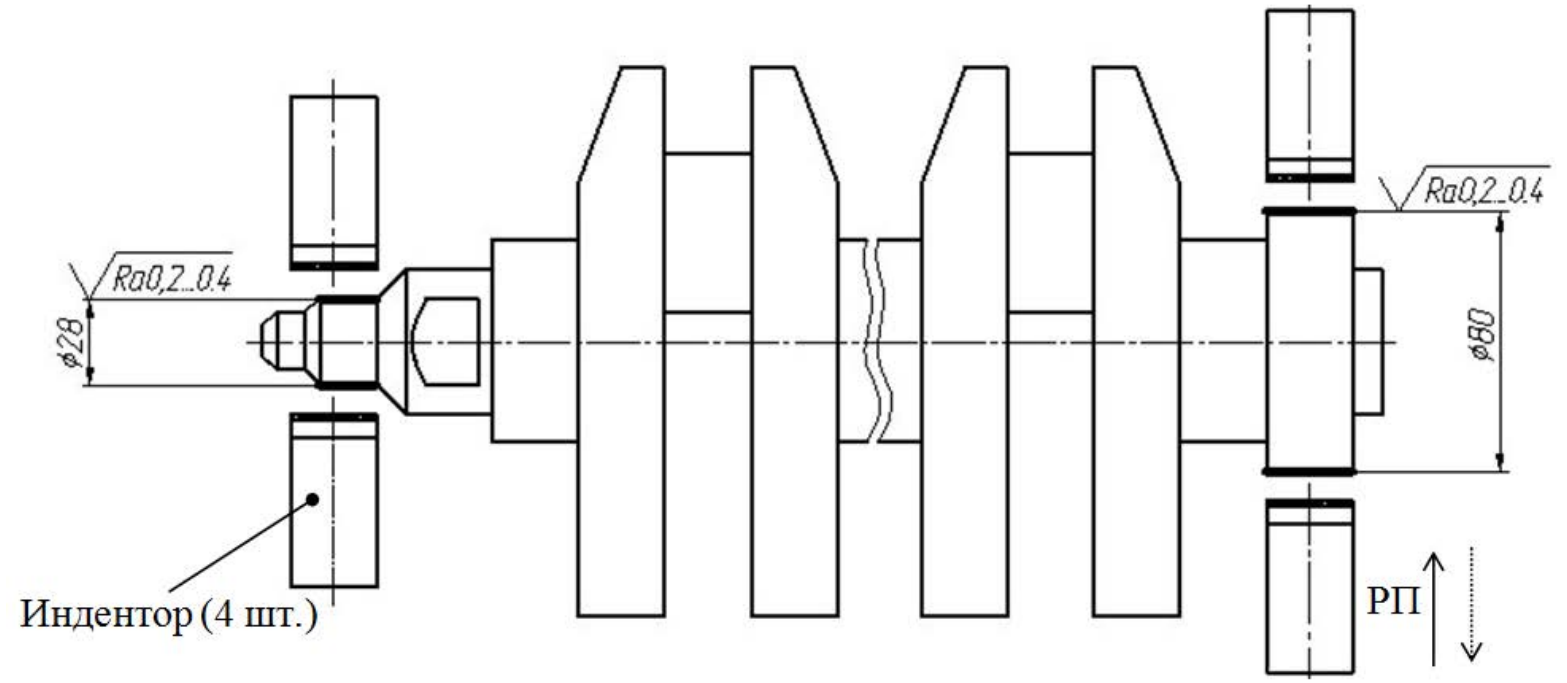

\section{Рисунок 1 - Технологическая наладка процесса выглаживания широким самоустанавливающимся инструментом.}

Ниже приведена иллюстрацию показывающая различие принципиальных схем процессов обработки полированием и выглаживанием. При полировании поверхности чугунной детали ввиду невысокой воспринимаемой нагрузки обработанная поверхность выглядит иныче, чем при выглаживании образом [5]. Процесс полирования можно сравнить с процессом резания (см. Рисунок 2,a), где каждое зерно является своеобразным резцом. На поверхности обработанной полированием видны борозды от обработки. Поверхность содержит большое количество графитовых включений с торчащими заусенцами. При выглаживании поверхности чугунной детали происходит интенсивная пластическая деформация металлической основы, а также выкрашивание графита из сферолитов который удаляется с СОТС (см. Рисунок 2,б). При этом возникает увеличение сплошности поверхностного слоя. На поверхности видны микротрещины, заусенцы сферолитов подмяты, но не закрыты.

Результаты экспериментального исследования микротвердости по сравнению с базовым технологическим процессом - полированием показали приращения данного показателя на 25\% (материал детали чугун марки ВЧ 75-50-03), при сохранении параметров микрогеометрии ( $\mathrm{Ra}=0,2 \ldots 0,4$ мкм, рис) в заданных пределах (Рисунок 3 ).

В ходе выполнения совместных научно-исследовательских и опытноконструкторских работ между Тольяттинским государственным университетом и ОАО «АВТОВАЗ» по теме «Совершенствование финишной обработки наружных цилиндрических поверхностей деталей автомобилей ВАЗ на основе технологии безсожевого поверхностного пластического деформирования» была внедрена технология выглаживания широким самоустанавливающимся инструментом на финишной операции обработки сальниковых шеек вала коленчатого автомобилей Lada Приора и Калина. На рисунке 4 представлена рабочая зона станка. 


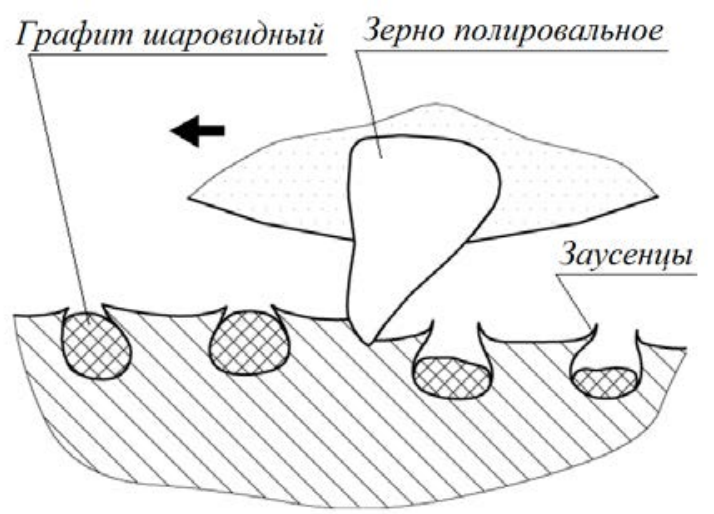

a)

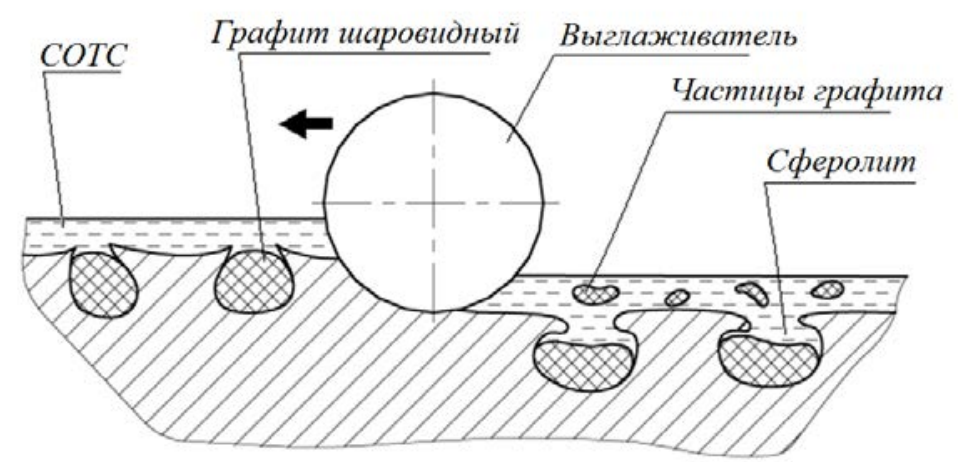

б)

Рисунок 2 - Схематичное сравнение процессов обработки:

а) полированием; б) выглаживанием.

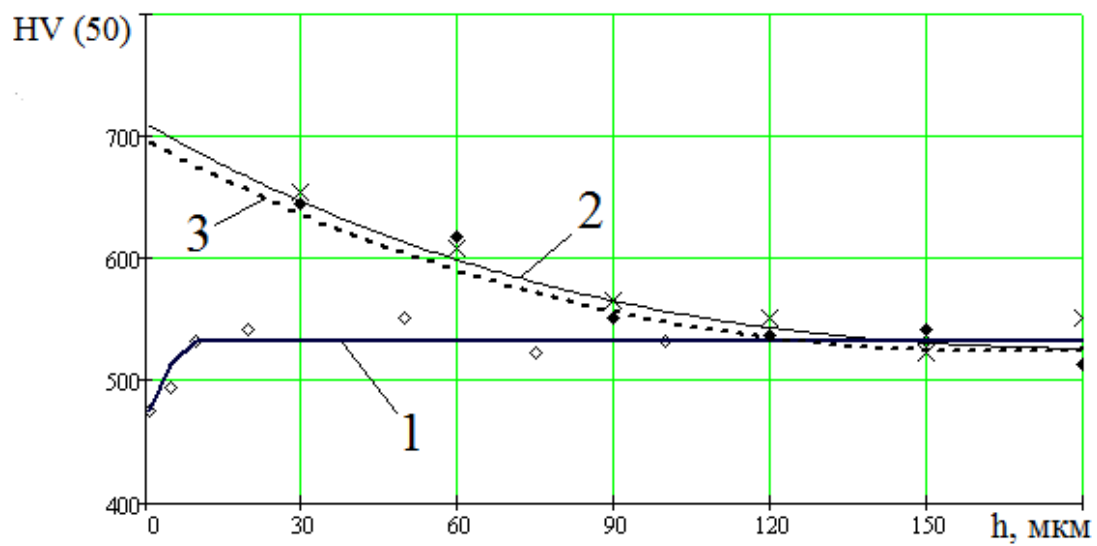

Рисунок 3 - Микротвердость поверхности деталей из чугуна ВЧ 75-50-03 после различных методов обработки: 1 - после полирования; 2 - после выглаживания с СОТС, 3 - после выглаживания без СОТС.

Преимущества получаемые при внедрении широкого выглаживания рассмотренные выше подтверждены как теоретическими, так и экспериментальными исследованиями. Получаемые при обработке широким выглаживанием качества поверхности (например, напряжения сжатия) положительно влияют на эксплуатационные свойства изделия [6, 7, 8]. Поскольку невозможно привести конкретные цифры, если принять уровень дефектов существовавший в год внедрения технологии за начальную точку очевидно дальнейшее его планомерное снижения. 


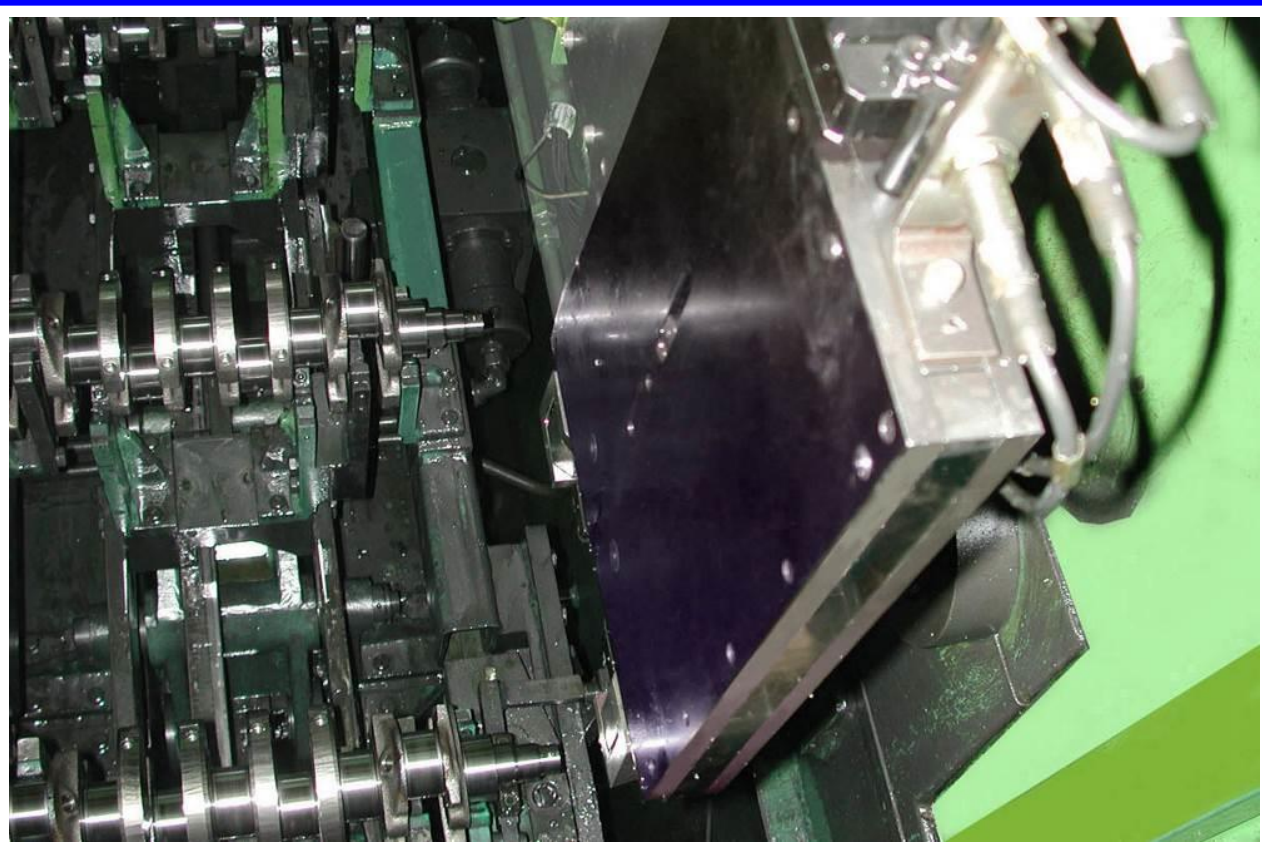

\section{Рисунок 4 - Рабочая зона станка для обработки выглажванием широким самоустанавливающимся инструментом.}

Постепенное изменение уровня дефектов объясняется тем (см. Рисунок 5), что гарантийный срок обслуживания на данную номенклатуру изделий составляет три года и соответственно к четвертому году работы модернизированного оборудования в статистические данные не включены обработанные с помощью полирования детали.

Уровень на 1000 aвт.

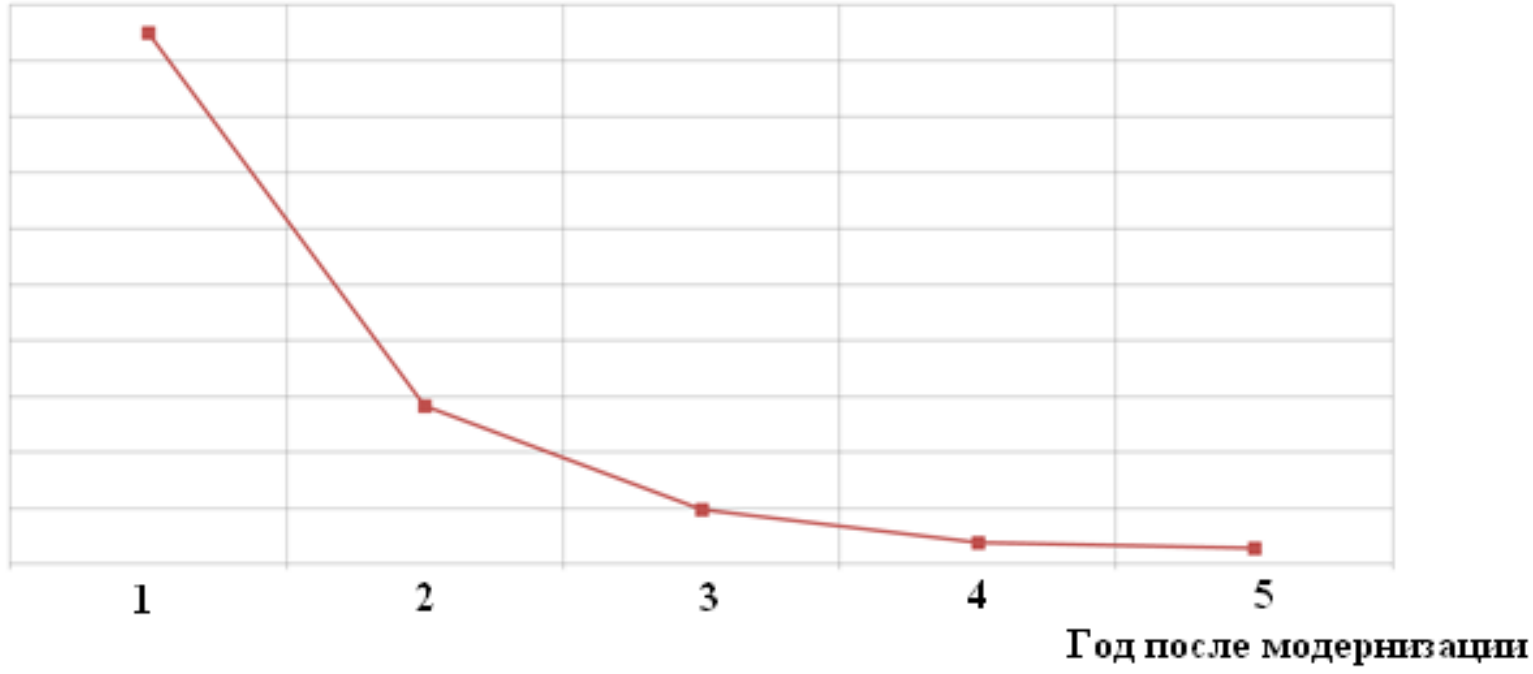

Рисунок 5 - Уровень дефектов сальников коленчатого вала на 1000 автомобилей в год.

Дальнейшее совершенствование технологии обработки выглаживанием является актуальным для машиностроения [9, 10]. Совершенствование начальных признаков технологии (возможности снижения шероховатости заготовок и повышения их микротвердости) дополняется большим спектром возможностей (нанесение многофункционального манометрического микрорельфа на поверхность изделий). Исследования в данном направления позволят повысить эксплуатационную надежность 
изделий отечественного машиностроения и его привлекательность для отечественных и зарубежных потребителей.

Проведение научно-исследовательской работь осуществляется при поддержке гранта Президента Российской Федераџии МК-6076.2013.8.

\section{Список литературы:}

1. Бобровский Н.М., Бобровский И.Н., Ежелев А.В., Мельников П.А. Технология обработки деталей поверхностно-пластическим деформированием без применения смазывающе-охлаждающих технологических средств. Самара: Самарский научный центр РАН, 2012. 142 с. ISBN 987-5-93424-598-7.

2. Бобровский Н.М. Разработка научных основ процесса обработки деталей поверхностно-пластическим деформированием без применения смазочноохлаждающих жидкостей. Тольятти: Тольяттинский государственный университет, 2008. $170 \mathrm{c}$.

3. Бобровский Н.М., Мельников П.А., Бобровский И.Н., Ежелев А.В. Гиперпроизводительный способ обработки поверхностно-пластическим деформированием // Современные проблемы науки и образования. 2013. № 5. URL: www.science-education.ru/111-10239 (дата обращения: 26.02.2014).

4. Бобровский Н.М., Ежелев А.В., Мельников П.А., Бобровский И.Н. Устройство для гиперпроизводительной финишной обработки поверхностей деталей выглаживанием // Известия Самарского научного центра Российской академии наук. 2012. T. 14. № 6-1. С. 93-96.

5. Бобровский Н. М., Мельников П. А., Бобровский И. Н., Ежелев А. В., Лукьянов А. А. Исследование влияния режимов обработки на шероховатость поверхности закаленных валов в условиях массового производства // Современные проблемы науки и образования. 2011. № 5. URL:www.science-education.ru/99-4791 (дата обращения: 26.02.2014).

6. Бобровский И.Н. Повышение эксплуатационной надежности деталей автомобилей и экологичности их изготовления за счет освоения новой технологии широкого выглаживания : дис. ... канд. техн. наук. М.: Московский государственный технологический университет, 2011. 187 с.

7. Мельников П.А. Повышение эффективности технологии выглаживания широким самоустанавливающимся инструментом без смазочно-охлаждающей жидкости: автореф. дис. ... канд. техн. наук. Самара: Самарский государственный технический университет, 2008. 20 с.

8. Бобровский Н.М., Мельников П.А. Оптимизация параметров процесса выглаживания в производственных условиях с целью получения поверхности, пригодной для работы в условиях гидродинамического трения // Вектор науки ТГУ. 2011. № 2. С. 65-67.

9. Бобровский Н.М., Барабанов С.И., Максименко Н.Н., Бобровский И.Н. Оценка качества методов обработки ППД без применения смазочно-охлаждающих жидкостей // Известия Самарского научного центра Российской академии наук. 2008. № 6. С. 37-44.

10. Мельников П.А., Селиванов А.С., Хамидуллова Л.Р. Повышение эксплуатационных свойств сальниковых шеек коленчатых валов путем оптимизации технологии изготовления // Объединенный научный журнал. 2003. № 29. С. 15-17. 